\title{
Current appraisal of single inhaler triple therapy in COPD
}

This article was published in the following Dove Press journal:

International Journal of COPD

\section{Brian Lipworth \\ Chris RuiWen Kuo \\ Sunny Jabbal}

Division of Molecular \& Clinical Medicine, Scottish Centre for Respiratory Research, Ninewells Hospital and Medical School, University of Dundee, Scotland, UK
Correspondence: Brian Lipworth Division of Molecular \& Clinical Medicine, Scottish Centre for Respiratory Research, Ninewells Hospital and Medical School, University of Dundee, DDI 9SY, Scotland, UK

Email b.j.lipworth@dundee.ac.uk
Abstract: A single inhaler containing inhaled corticosteroid (ICS)/long-acting beta-agonist (LABA)/long-acting muscarinic antagonist (LAMA) is a more convenient way of delivering triple therapy in patients with COPD. Single triple therapy has been shown to be superior at reducing exacerbations and improving quality of life compared to LABA/LAMA, especially in patients with a prior history of frequent exacerbations and blood eosinophilia, who have ICS responsive disease. The corollary is that patients with infrequent exacerbations who are noneosinophilic may be safely de-escalated from triple therapy to LABA/LAMA without loss of control. Pointedly, there is a substantially increased risk of pneumonia associated with the triple therapy containing fluticasone furoate but not beclometasone dipropionate or budesonide. Since triple therapy is also better than ICS/LABA at reducing exacerbations and improving lung function, symptoms, and quality of life, this brings into question the rationale for using ICS/ LABA. Hence, we propose a simplified pragmatic decision process based on symptoms, prior to exacerbation history, and blood eosinophils to select which patients should be given a single triple inhaler or LABA/LAMA. Differences in patient preference of inhaler device, formulations and drugs will also determine which triple inhaler prescribers elect to use.

Keywords: COPD, inhaled corticosteroid, long-acting beta-agonist, long-acting muscarinic antagonist, lung function, exacerbation

\section{Introduction}

Single inhaler triple therapy containing inhaled corticosteroid (ICS) with long-acting beta-agonist (LABA) and long-acting muscarinic antagonist (LAMA) has been advocated for frequently exacerbating COPD patients, corresponding to group D of the GOLD guidelines. ${ }^{1}$ In light of recent clinical trials evaluating fluticasone furoate/ vilanterol/umeclidinium (FF/VIL/UMEC) and beclometasone dipropionate/formoterol/ glycopyrronium (BDP/FM/GLY), ${ }^{2,3}$ we thought it would be timely to briefly reappraise the current data of these two available closed single triple inhalers, especially in light of other pertinent data on open triple therapy (ie, two separate inhalers) for COPD.

The essential premise for using a triple inhaler in COPD, aside from improved adherence, is that the ICS moiety will reduce exacerbations by suppressing the eosinophilic component of inflammation, while the LABA/LAMA will improve symptoms and exacerbations by improving airway caliber due to bronchodilator effects on airway smooth muscle (Figure 1). In addition, LAMA might also exhibit putative anti-inflammatory activity by antagonizing the paracrine mediated effects of acetylcholine on mucosal inflammatory cell chemotaxis and activation in addition to reducing mucus hypersecretion. ${ }^{4}$ The potential downside of ICS is the potential for increased pneumonia risk, which raises the fundamental question regarding the overall relative benefit-risk equation (Figure 1). For example, in the TORCH trial comparing fluticasone propionate/salmeterol 

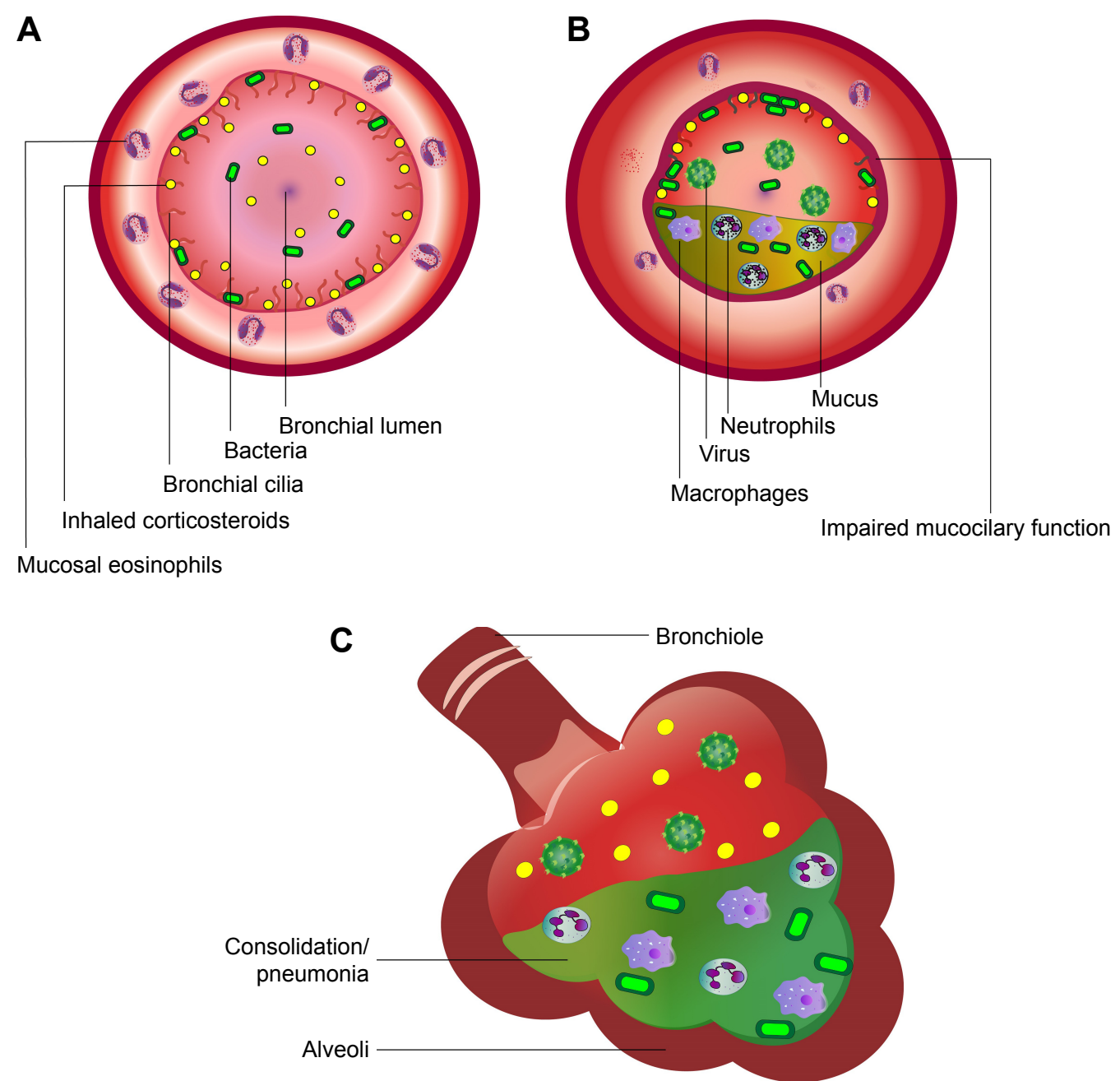

Figure I Schematic to show effects of inhaled corticosteroid (ICS) moiety of single triple inhaler therapy in COPD.

Notes: (A, B) The benefit is shown as attenuation of bronchial mucosal eosinophilic inflammation resulting in reduced exacerbations; (B, C) risk depicted as impaired mucociliary function with mucus retention and altered microbiome following initial viral infection, along with prolonged bronchial/alveolar ICS retention and resulting local immunosuppression, in turn producing consolidation (pneumonia).

(FP/SM) vs SM alone over 3 years, the number needed to treat was calculated as 44 to prevent one exacerbation and 16 to induce one pneumonia episode, giving a relative benefit-risk ratio for FP of 2.75. ${ }^{5}$ In this regard, there has been shown to be a marked difference in dose-related risk of serious pneumonia comparing FP and budesonide (BUD) in COPD. ${ }^{6}$

Considering the currently available triple inhalers, FF/VIL/ UMEC is a once daily dry powder inhaler (DPI) formulation (Trelegy Ellipta; GSK, Uxbridge, UK) while the BDP/FM/ GLY is a twice daily solution extra fine particle pressurized metered dose inhaler (pMDI) formulation (Trimbow; Chiesi, Parma, Italy). Patient preference and ability to use the different formulations will be important in determining which inhaler is best for an individual patient.

There is also a third triple cosuspension pMDI formulation (PT010 Aerosphere; Luton, UK) in development currently in Phase III trials containing BUD with FM/GLY.

\section{ICS withdrawal trials}

In terms of determining the potential impact of the ICS moiety, it is pertinent to first consider the two pivotal trials which have looked at ICS withdrawal from prior open triple therapy.

The WISDOM randomized double blind trial enrolled 2,485 patients who had experienced at least one exacerbation in the previous year. ${ }^{7}$ Seventy percent of patients were taking prior ICS at baseline and 49\% were on open triple therapy. After an initial run-in on open triple therapy with FP/SM with tiotropium (TIO), patients were then randomized to continue on triple therapy (ICS continuation group) or SM/TIO (ICS withdrawal group) for 1 year. There was no difference in the primary end point of exacerbations but a significant $43 \mathrm{~mL}$ mean fall in $\mathrm{FEV}_{1}$ after ICS withdrawal and no difference in pneumonia incidence. Post hoc analysis revealed a $43 \%$ increase in exacerbations after ICS withdrawal in those 
patients who had blood eosinophils of at least 300 cells $/ \mu \mathrm{L}$ in conjunction with two or more exacerbations in the past year, whereas there was no difference in patients with eosinophils less than $300 / \mu \mathrm{L} .^{8}$

The SUNSET randomized double blind trial in 1,033 patients over 26 weeks looked at treatment de-escalation involving ICS withdrawal in infrequently exacerbating patients on prior triple therapy who, after initial run-in on $\mathrm{FP} / \mathrm{SM} / \mathrm{TIO}$ were then randomized to continue on open triple therapy or stepped down to once daily indacaterol/ glycopyrronium (IND/GLY) via DPI. ${ }^{9}$ There was a $26 \mathrm{~mL}$ difference in the primary end point of $\mathrm{FEV}_{1}$ and an $8 \%$ difference in exacerbations neither of which were significant. However, among $23 \%$ of patients who had blood eosinophils of at least $300 / \mu \mathrm{L}$, there was a $69 \mathrm{~mL}$ lower mean $\mathrm{FEV}_{1}$ and $47 \%$ increase in exacerbations which were both significant.

\section{Real-life observational studies}

Real-life observational data from a UK primary care database of GOLD A or B patients have also shown no differences in health resource use comparing open triple therapy vs LABA/LAMA. ${ }^{10}$ The DACCORD real-life observational study from Germany looked at 377 infrequently exacerbating patients mostly GOLD B, who were switched to IND/GLY having previously been taking open triple therapy. ${ }^{11}$ Over the 1 year of follow-up after switching, there was no increase in exacerbations while $52 \%$ had a clinically relevant improvement in COPD Assessment Test score. Finally, in a Scottish observational study involving a time-dependent analysis of 2,853 patients followed-up for 4.5 years, taking once daily TIO along with twice daily ICS/ LABA as separate inhalers was associated with $29 \%$ fewer exacerbations, $15 \%$ fewer hospital admissions, and 35\% lower all-cause mortality compared to ICS/LABA alone. ${ }^{12}$

Taken together, these ICS withdrawal trials and observational studies indicate that among infrequently exacerbating GOLD B patients who were inappropriately receiving prior triple therapy, stepping down to LABA/LAMA appears to be a safe and cogent option, perhaps with the caveat that caution is required for the quarter of patients who have eosinophilic COPD.

Table I Key trials of single triple inhaler ICS/LABA/LAMA vs dual inhalers as either ICS/LABA or LABA/LAMA

\begin{tabular}{|c|c|c|c|c|c|}
\hline Study & Treatments & $\begin{array}{l}\text { Exacerbation } \\
\text { rate/year }\end{array}$ & $\begin{array}{l}\text { Difference/ } \\
\text { year }\end{array}$ & $\%$ difference & $\begin{array}{l}\text { Time } \\
\text { to treat } \\
\text { (years) }\end{array}$ \\
\hline IMPACT* & $\begin{array}{l}\text { ICS/LABA/LAMA } \\
(\mathrm{n}=4,15 \mathrm{I}) \text { vs } \\
\text { ICS/LABA } \\
(\mathrm{n}=4,134)\end{array}$ & 0.91 vs 1.07 & 0.16 & 15 & 6.25 \\
\hline IMPACT** & $\begin{array}{l}\text { ICS/LABA/LAMA }(n=4, I 5 I) \text { vs } \\
\text { LABA/LAMA } \\
(n=2,070)\end{array}$ & 0.91 vs 1.21 & 0.30 & 25 & 3.33 \\
\hline IMPACT* & $\begin{array}{l}\text { ICS/LABA } \\
(n=4,134) \text { vs } \\
\text { LABA/LAMA } \\
(n=2,070)\end{array}$ & I.07 vs 1.21 & 0.14 & 12 & 7.14 \\
\hline TRIBUTE* & $\begin{array}{l}\text { ICS/LABA/LAMA }(n=764) \text { vs } \\
\text { LAMA/LABA } \\
(n=768)\end{array}$ & 0.50 vs 0.59 & 0.09 & 15 & II.II \\
\hline TRILOGY & $\begin{array}{l}\text { ICS/LABA/LAMA }(n=687) \text { vs } \\
\text { ICS/LABA } \\
(n=680)\end{array}$ & $0.4 \mathrm{I}$ vs 0.53 & 0.12 & 23 & 8.33 \\
\hline FULFIL & $\begin{array}{l}\text { ICS/LABA/LAMA }(\mathrm{n}=91 \mathrm{I}) \text { vs } \\
\text { ICS/LABA } \\
(\mathrm{n}=899)\end{array}$ & 0.22 vs 0.34 & 0.12 & 35 & 8.33 \\
\hline KRONOS & $\begin{array}{l}\text { ICS/LABA/LAMA (640) vs } \\
\text { LABA/LAMA (627) }\end{array}$ & 0.46 vs 0.95 & 0.49 & 52 & 2.04 \\
\hline KRONOS & $\begin{array}{l}\text { ICS/LABA/LAMA (640) vs } \\
\text { ICS/LABA }(3 \mid 6)\end{array}$ & 0.46 vs 0.56 & 0.10 & 18 & 10.0 \\
\hline KRONOS & $\begin{array}{l}\text { ICS/LABA }(316) \text { vs } \\
\text { LABA/LAMA (637) }\end{array}$ & 0.56 vs 0.95 & 0.39 & 41 & 2.56 \\
\hline
\end{tabular}

Notes: Data for each trial are shown as number of patients, moderate-severe exacerbation rate, absolute difference, percent relative reduction and time to treat (ie, number of years on treatment required to reduce one exacerbation in an average patient ). Key trials include: IMPACT, ${ }^{2} \mathrm{TRIBUTE}^{3} \mathrm{FULFIL}^{13} \mathrm{TRILOGY}^{15} \mathrm{KRONOS}^{26}$ Asterisk denotes exacerbations were the primary end point.

Abbreviations: ICS, inhaled corticosteroid; LABA, long-acting beta-agonist; LAMA, long-acting muscarinic antagonist. 


\section{Randomized controlled trials with single triple inhalers}

There are four key randomized controlled trials that have compared single triple to dual combination inhalers (Table 1). The first key trial is the FULFIL study ranging over 24 weeks in 1,810 patients ( $53 \%$ GOLD B, 38\% GOLD D) comparing FF/VIL/UMEC vs BUD/FM (turbuhaler), which for coprimary end points showed significant mean differences amounting to $171 \mathrm{~mL}$ in $\mathrm{FEV}_{1}$ and 2.2 units in St George's Respiratory Questionnaire. ${ }^{13}$ Although there was a relative $35 \%$ reduction in annualized exacerbations conferred by the triple inhaler, absolute exacerbation rates were low. There was also a significant difference in pneumonia rates which were $2.2 \%$ and $0.8 \%$ for FF/VIL/UMEC vs BUD/FM respectively. However, this study may be criticized for comparing different ICS and LABA moieties via different DPI devices as well as once vs twice daily dosing regimes. As such these data are of limited value in terms of informing clinical decision-making.

The second trial is the IMPACT study which compared $\mathrm{FF} / \mathrm{VIL} / \mathrm{UMEC}$ to either VIL/UMEC or FF/VIL in 10,355 patients over 1 year, all given once daily via the Ellipta device (GSK, Uxbridge, UK), powered on exacerbations. ${ }^{2}$ For the primary end point triple therapy reduced exacerbations by $25 \%$ vs VIL/UMEC and $15 \%$ vs FF/VIL. The difference in exacerbations occurred within the first month of randomized treatment and thereafter the rates were parallel. The relative reduction in exacerbations comparing triple therapy to VIL/ UMEC was $32 \%$ for blood eosinophils of at least $150 / \mu \mathrm{L}$ and $12 \%$ for less than $150 / \mu \mathrm{L}$, with only the former being significant. For lung function in comparison to triple therapy there was a $54 \mathrm{~mL}$ significant mean difference in $\mathrm{FEV}_{1}$ for vs VIL/UMEC and $97 \mathrm{~mL}$ vs FF/VIL, while for SGRQ the mean difference was -1.18 for both of the same comparisons. The transition dyspnea index (TDI) showed a significantly higher proportion of responders with triple vs either dual therapy. Pneumonia rates per 1,000 patient-years were 96 for triple therapy (8\%), 97 for FF/VIL (7\%), and 61 for VIL/UMEC $(5 \%)$, amounting to respective increased risks of $57 \%$ and $58 \%$ relative to VIL/UMEC. Compared to VIL/UMEC the on-treatment all-cause mortality rates were $42 \%$ and $39 \%$ lower with triple therapy and FF/VIL, respectively.

In summary, IMPACT ${ }^{2}$ showed that using two bronchodilators in a single triple inhaler is better at reducing exacerbations than using one as ICS/LABA, while the ICS moiety in the triple inhaler reduces exacerbations compared to LABA/ LAMA in the eosinophilic phenotype. However, the FF moiety in the triple inhaler or ICS/LABA had the downside of a substantially increased pneumonia risk. The relative benefit-risk ratio for FF/VIL vs VIL alone has previously been calculated for severe exacerbations and pneumonias requiring hospital admission in relation to blood eosinophils. For eosinophils $>2 \%$, there were 1.5 exacerbations prevented with FF in relation to inducing two pneumonias, while for $>4 \%$, there were five exacerbations and two episodes of pneumonias, per 100 patients over 1 year. ${ }^{14}$ The relative benefit-risk ratio for the triple inhaler in patients with counts of at least $300 / \mu \mathrm{L}$ remains to be established with regard to exacerbations and pneumonia.

In the TRILOGY study, a head-to-head comparison over 1 year was made of BDP/FM/GLY to BDP/FM both twice daily via pMDI in 1,368 patients who were mostly GOLD B. ${ }^{15}$ For the coprimary end points of trough and peak $\mathrm{FEV}_{1}$, the triple inhaler was superior by $81 \mathrm{~mL}$ and $117 \mathrm{~mL}$, respectively, compared to ICS/LABA, reflecting the additional bronchodilator effect of the LAMA. The third coprimary end point showed no significant difference in mean TDI score. In addition, for the secondary end point there was a $23 \%$ relative reduction in exacerbations with the triple inhaler, although absolute exacerbations rates were low in both treatment arms (Table 1).

The TRIBUTE study, over 1 year, compared BDP/FM/ GLY twice daily to IND/GLY once daily in 1,532 patients who were mostly GOLD B. ${ }^{3}$ The reason for choosing IND/GLY as the comparator arm was that it had been shown to be superior to FM/SM on exacerbations in the FLAME study. ${ }^{16}$ For the primary end point of exacerbations, there was a $15 \%$ overall relative reduction in favor of the triple inhaler but again absolute rates in both treatments were quite low (Table 1) and no overall difference was found in time to first exacerbation. In patients with eosinophils of at least $2 \%$ the difference in exacerbations was $19 \%$ compared to $6 \%$ in those with eosinophils less than $2 \%$. Moreover, there were small but significant differences in trough $\mathrm{FEV}_{1}$ and SGRQ over the 52 weeks, while pneumonia occurred in $4 \%$ of patients in both groups.

Comparing TRIBUTE and IMPACT ${ }^{2,3}$, there are some important differences to point out. First, in IMPACT, 38\% of patients were on prior triple therapy but none in TRIBUTE, whereas in both studies, over $60 \%$ of patients had been taking prior ICS. We wonder if perhaps acutely stopping ICS in patients subsequently receiving LABA/LAMA might in part explain the increased exacerbation risk which was evident in the first month of treatment in IMPACT. Such an effect of ICS cessation was not observed in WISDOM or SUNSET, although the latter enrolled patients with an infrequent exacerbation history. Another key difference is that $47 \%$ and 


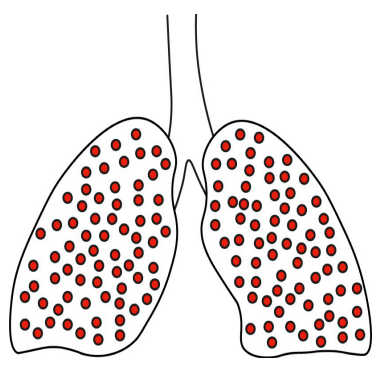

FF

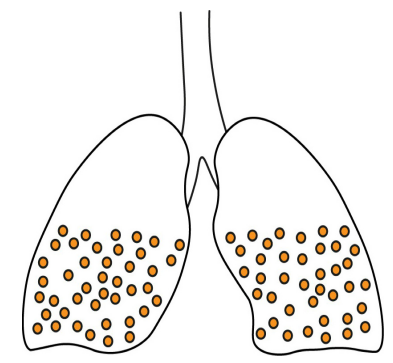

FP

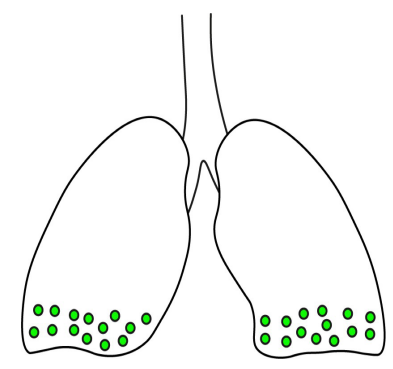

BUD/BDP

Figure 2 Duration of lung retention with inhaled corticosteroids due to relative lipophilicity, which in turn determines pneumonia risk in COPD.

Note: Fluticasone furoate (FF), fluticasone propionate (FP), budesonide (BUD), and beclometasone dipropionate (BDP: via its active metabolite I7-BMP) - schematically depicted to reflect their respective kinetic terminal elimination half lives (FF $>$ FP $>B U D / B D P)$

Abbreviation: 17-BMP, 17-beclometasone monopropionate.

$21 \%$ of patients in IMPACT and TRIBUTE, respectively, at baseline had experienced two or more exacerbations in the previous year. Having said that patients in TRIBUTE $\left(\mathrm{FEV}_{1}\right.$ $36 \%$ ) had more severe airflow limitation than in IMPACT $\left(\mathrm{FEV}_{1} 46 \%\right)$. This difference in exacerbation history probably explains the greater relative and absolute reduction in exacerbations in IMPACT vs TRIBUTE when comparing triple to dual bronchodilator therapy. Furthermore, IMPACT compared identical LABA/LAMA moieties in both arms via the same once daily DPI device, whereas in TRIBUTE, the comparison was twice daily pMDI vs once daily DPI with different LABAs but the same LAMA, although in different dosing regimens. The other major difference between the studies was the pneumonia signal seen in IMPACT but not TRIBUTE in association with the FF moiety.

The relative increase in pneumonia risk seen in IMPACT and FULFIL but not TRIBUTE can be explained by the much higher degree of lipophilicity of FF than BDP (via its active metabolite 17-beclometasone monopropionate). ${ }^{17}$ The higher lipophilicity results in more prolonged ICS retention in the lung and in turn greater local immunosuppression in the presence of impaired mucociliary clearance and altered lung microbiome in patients with COPD (Figure 2). The differences in lipophilicity are reflected in inhaled pharmacokinetics with terminal elimination half lives being 24 hours vs 2.3 hours for FF and BMP, respectively. ${ }^{18,19}$ The prolonged duration of lung retention with $\mathrm{FF}$ is evident in patients with asthma where FeNO remains suppressed for up to 18 days after stopping treatment with FF compared to up to 7 days after stopping FP. ${ }^{20,21}$ It is unclear as to whether the more frequent exacerbating phenotype in IMPACT might in part explain the increased pneumonia risk, aside from the particular pharmacologic properties of FF. Interestingly the increased total and peripheral lung deposition associated with the extra fine formulation of BDP did not translate into an increased pneumonia risk in TRIBUTE. Another possibility worth considering is that the extra fine BDP particles have lower oropharyngeal deposition than the more coarse particles of FF which could also alter the local microbiome. Studies are indicated to assess the benefit-risk profile of BDP/ FM/GLY when given via spacer device, particularly in more frequently exacerbating patients who may not only derive more benefit but also may be more prone to pneumonia.

\section{Conclusions and the way forward}

In summary, single inhaler triple therapy appears to be a suitable option for frequently exacerbating GOLD D patients, particularly those who have the eosinophilic phenotype. Since single triple inhaler has been shown to be consistently superior compared to ICS/LABA, we believe that there is probably no role moving forward for ICS/LABA in COPD guidelines. Hence, to simplify prescribing for COPD, we advocate a pragmatic approach to reduce exacerbations using single inhaler therapy with either triple therapy or LABA/LAMA based on exacerbation history and blood eosinophils. ${ }^{1}$ For more symptomatic GOLD B patients, we would advocate LABA/LAMA as a logical starting point given that this has been shown to be superior to LAMA or LABA alone. ${ }^{22,23}$ Nonetheless, we believe escalation to single triple inhaler might be warranted if patients continue to exacerbate on LABA/LAMA, although prospective trials are warranted to evaluate this strategy.

The beneficial effects of triple inhaler therapy compared to $\mathrm{LABA} / \mathrm{LABA}$ are predominantly seen in ICS reducing eosinophil driven exacerbations rather than improving lung function, symptoms, or quality of life. ICS will not however impact on infective or pauci-inflammatory-related exacerbations. Raised blood eosinophil counts on their own should not be used to inform decision-making with regard to using ICS as triple therapy, but rather in conjunction with exacerbation history. In this regard, we would suggest 
at least two exacerbations in the past year or one requiring hospital admission as a starting point. The difficult question is what eosinophil cutoff value should be used in a clinical setting to decide who goes onto triple therapy rather than LABA/LAMA. Based on the available data, we would advocate a pragmatic cutoff value for blood eosinophils of at least $300 / \mu \mathrm{L}$, which in an average patient would translate into a clinically meaningful reduction in exacerbation risk. However, trying to dichotomize what is a continuous variable may be somewhat arbitrary in terms of clinical decision-making in an individual patient. In such cases of eosinophilic COPD, it would be interesting to know if perhaps combining blood eosinophils with FeNO might improve the predictive value of ICS response, although in former smokers. At present, there are no defined thresholds for FeNO in COPD in terms of predicting ICS response in exacerbations, although this is likely to be lower than in asthma. ${ }^{24}$ In patients with so-called asthma COPD overlap a cutoff value of $22 \mathrm{ppb}$ has been proposed..$^{25}$ It is interesting to speculate if, eg, a combination of FeNO $\geq 20 \mathrm{ppb}$ and blood eosinophils $\geq 150 / \mu \mathrm{L}$ might be more predictive of identifying an ICS responsive phenotype than perhaps using eosinophils alone. Further work is needed to more clearly identify such threshold values for FeNO in COPD.

Differences in terms of the device and dosing regimen should be taken into account when considering which formulation to choose for an individual patient, along with the increased pneumonia risk associated with FF/VIL/UMEC. Any patient with COPD who has had a recent episode of pneumonia while taking ICS should have their treatment reappraised along with investigation to exclude concomitant bronchiectasis. Moreover, we believe that there are cogent reasons for not choosing to use FF as single triple therapy in patients who have COPD and bronchiectasis because of increased ICS lipophilicity and associated pneumonia risk in such individuals, especially when there are equally effective but safer options such as BDP and BUD.

Further studies are warranted to look at the potential benefit-risk profile of triple inhalers in GOLD B patients who experience an exacerbation despite already taking LABA/ LABA, particularly those with raised blood eosinophils. The KRONOS trial over 24 weeks was performed in predominantly GOLD B patients with $\mathrm{FEV}_{1}$ of $50 \%$ in whom $72 \%$ were taking prior ICS. There were significant improvements over 24 weeks in the primary end points comparing the cosuspension formulations of BUD/FM/GLY versus BUD/FM amounting to a $104 \mathrm{~mL}$ difference in peak $\mathrm{FEV}_{1}$, and a 22 $\mathrm{mL}$ difference comparing BUD/FM/GLY versus FM/GLY in trough $\mathrm{FEV}_{1} \cdot{ }^{26}$ For the secondary end point BUD/FM/
GLY was associated with 52\% significantly fewer moderate to severe exacerbations compared to FM/GLY with no difference in pneumonia events ( $2 \%$ in both groups). The difference in exacerbations was more pronounced in patients with eosinophil counts above $150 / \mu \mathrm{L}$. Comparing BUD/FM/ GLY versus BUD/FM there were $18 \%$ fewer exacerbations which was not significant. There was also a significant 1.22 difference in SGRQ comparing BUD/FM/GLY vs FM/ GLY. Given the lack of any increased pneumonia risk with the triple, this in turn suggests that even in infrequently exacerbating patients there may be a role for BUD/FM/GLY being prescribed de novo rather than FM/GLY especially in eosinophilic patients. However these results should be interpreted with a degree of caution due to the 6 months duration and exacerbations being a secondary end point, along with $44 \%$ of patients being reversible. The results ETHOS study (NCT02465567) are eagerly awaited which will look at two dose strengths of BUD/FM/GLY over 12 months compared to BUD/FM and FM/GLY in more severe patients, powered on exacerbations.

Finally, clinicians should always consider the possibility of de-escalating from triple therapy to LABA/LAMA in infrequently exacerbating noneosinophilic patients with COPD.

\section{Disclosure}

Dr Lipworth reports grants and personal fees from AZ, personal fees and other from Teva, personal fees from Novartis, nonfinancial support from GSK, grants and personal fees from Chiesi, grants and personal fees from Boerhinger, during the conduct of the study; grants and personal fees from Meda/ Mylan, grants from Janssen, grants from Roche, personal fees from Lupin, grants and personal fees from Boerhinger Ingelheim, grants and personal fees from Chiesi, personal fees from Cipla, personal fees from Sandoz, personal fees from Dr Reddys, grants and personal fees from Sanofi, personal fees from Circassia, outside the submitted work. Dr Kuo reports personal fees and nonfinancial support from Pfizer, outside the submitted work. Dr Jabbal reports personal fees and nonfinancial support from Chiesi Pharma, personal fees and nonfinancial support from Pfizer, nonfinancial support and other from Napp, personal fees and nonfinancial support from AstraZeneca, nonfinancial support from Teva, personal fees and nonfinancial support from Mylan, personal fees from Boehringer Ingelheim, outside the submitted work. The authors report no other conflicts of interest in this work.

\section{References}

1. Lipworth B, Jabbal S. A pragmatic approach to simplify inhaler therapy for COPD. Lancet Respir Med. 2017;5(9):679-681. 
2. Lipson DA, Barnhart F, Brealey N, et al. Once-daily single-inhaler triple versus dual therapy in patients with COPD. $N$ Engl J Med. 2018;378(18):1671-1680.

3. Papi A, Vestbo J, Fabbri L, et al. Extrafine inhaled triple therapy versus dual bronchodilator therapy in chronic obstructive pulmonary disease (TRIBUTE): a double-blind, parallel group, randomised controlled trial. Lancet. 2018;391(10125):1076-1084.

4. Kistemaker LE, Oenema TA, Meurs H, Gosens R. Regulation of airway inflammation and remodeling by muscarinic receptors: perspectives on anticholinergic therapy in asthma and COPD. Life Sci. 2012; 91(21-22):1126-1133

5. Suissa S. Number needed to treat in COPD: exacerbations versus pneumonias. Thorax. 2013;68(6):540-543.

6. Suissa S, Patenaude V, Lapi F, Ernst P. Inhaled corticosteroids in COPD and the risk of serious pneumonia. Thorax. 2013;68(11):1029-1036.

7. Magnussen H, Disse B, Rodriguez-Roisin R, et al. Withdrawal of inhaled glucocorticoids and exacerbations of COPD. N Engl J Med. 2014; 371(14):1285-1294.

8. Calverley PMA, Tetzlaff K, Vogelmeier C, et al. Eosinophilia, frequent exacerbations, and steroid response in chronic obstructive pulmonary disease. Am J Respir Crit Care Med. 2017;196(9):1219-1221.

9. Chapman KR, Hurst JR, Frent SM, et al. Long-term triple therapy de-escalation to indacaterol/glycopyrronium in patients with chronic obstructive pulmonary disease (SUNSET): a randomized, doubleblind, triple-dummy clinical trial. Am J Respir Crit Care Med. 2018; 198(3):329-339.

10. Chalmers JD, Poole C, Webster S, Tebboth A, Dickinson S, Gayle A. Assessing the healthcare resource use associated with inappropriate prescribing of inhaled corticosteroids for people with chronic obstructive pulmonary disease (COPD) in GOLD groups A or B: an observational study using the Clinical Practice Research Datalink (CPRD). Respir Res. 2018;19(1):63.

11. Worth H, Buhl R, Criée CP, Kardos P, Lossi NS, Vogelmeier CF. GOLD 2017 treatment pathways in 'real life': an analysis of the DACCORD observational study. Respir Med. 2017;131(131):77-84.

12. Short PM, Williamson PA, Elder DHJ, Lipworth SIW, Schembri S, Lipworth BJ. The impact of tiotropium on mortality and exacerbations when added to inhaled corticosteroids and long-acting $\beta$-agonist therapy in COPD. Chest. 2012;141(1):81-86.

13. Lipson DA, Barnacle H, Birk R, et al. FULFIL trial: once-daily triple therapy for patients with chronic obstructive pulmonary disease. Am J Respir Crit Care Med. 2017;196(4):438-446.

14. Suissa S, Ernst P. Precision medicine urgency: the case of inhaled Corticosteroids in COPD. Chest. 2017;152(2):227-231.

15. Singh D, Papi A, Corradi M, et al. Single inhaler triple therapy versus inhaled corticosteroid plus long-acting $\beta 2$-agonist therapy for chronic obstructive pulmonary disease (TRILOGY): a double-blind, parallel group, randomised controlled trial. Lancet. 2016;388(10048): 963-973.
16. Wedzicha JA, Banerji D, Chapman KR, et al. Indacaterol-glycopyrronium versus salmeterol-fluticasone for COPD. $N$ Engl J Med. 2016; 374(23):2222-2234.

17. Janson C, Stratelis G, Miller-Larsson A, Harrison TW, Larsson K. Scientific rationale for the possible inhaled corticosteroid intraclass difference in the risk of pneumonia in COPD. Int $J$ Chron Obstruct Pulmon Dis. 2017;12:3055-3064.

18. Allen A, Bareille PJ, Rousell VM. Fluticasone furoate, a novel inhaled corticosteroid, demonstrates prolonged lung absorption kinetics in man compared with inhaled fluticasone propionate. Clin Pharmacokinet. 2013;52(1):37-42.

19. Daley-Yates PT, Price AC, Sisson JR, Pereira A, Dallow N. Beclomethasone dipropionate: absolute bioavailability, pharmacokinetics and metabolism following intravenous, oral, intranasal and inhaled administration in man. Br J Clin Pharmacol. 2001;51(5):400-409.

20. Bardsley G, Daley-Yates P, Baines A, et al. Anti-inflammatory duration of action of fluticasone furoate/vilanterol trifenatate in asthma: a cross-over randomised controlled trial. Respir Res. 2018;19(1):133.

21. Anderson WJ, Short PM, Williamson PA, Lipworth BJ. Inhaled corticosteroid dose response using domiciliary exhaled nitric oxide in persistent asthma: the FENOtype trial. Chest. 2012;142(6):1553-1561.

22. Wedzicha JA, Decramer M, Ficker JH, et al. Analysis of chronic obstructive pulmonary disease exacerbations with the dual bronchodilator QVA149 compared with glycopyrronium and tiotropium (SPARK): a randomised, double-blind, parallel-group study. Lancet Respir Med. 2013;1(3):199-209.

23. Calverley PMA, Anzueto AR, Carter K, et al. Tiotropium and olodaterol in the prevention of chronic obstructive pulmonary disease exacerbations (DYNAGITO): a double-blind, randomised, parallel-group, active-controlled trial. Lancet Respir Med. 2018;6(5):337-344.

24. Mostafavi-Pour-Manshadi SM, Naderi N, Barrecheguren M, Dehghan A, Bourbeau J. Investigating fractional exhaled nitric oxide (FeNO) in chronic obstructive pulmonary disease (COPD) and asthma-COPD overlap (ACO): a scoping review protocol. BMJ Open. 2017;7(12): e018954.

25. Chen FJ, Huang XY, Liu YL, Lin GP, Xie CM. Importance of fractional exhaled nitric oxide in the differentiation of asthma-COPD overlap syndrome, asthma, and COPD. Int J Chron Obstruct Pulmon Dis. 2016; $11: 2385-2390$.

26. Ferguson GT, Rabe KF, Martinez FJ, et al. Triple therapy with budesonide/glycopyrrolate/formoterol fumarate with co-suspension delivery technology versus dual therapies in chronic obstructive pulmonary disease (KRONOS): a double-blind, parallel-group, multicentre phase 3 randomised controlled trial. Lancet Respir Med. 2018. Published on line Sept 16 doi.org/10.1016/S2213-2600(18)30327-8.

Dove Medical Press encourages responsible, free and frank academic debate. The content of the International Journal of Chronic Obstructive Pulmonary Disease 'Editorial' section does not necessarily represent the views of Dove Medical Press, its officers, agents, employees, related entities or the International Journal of Chronic Obstructive Pulmonary Disease editors. While all reasonable steps have been taken to confirm the content of each Editorial, Dove Medical Press accepts no liability in respect of the content of any Editorial, nor is it responsible for the content and accuracy of any Editorial.

International Journal of COPD

\section{Publish your work in this journal}

The International Journal of COPD is an international, peer-reviewed journal of therapeutics and pharmacology focusing on concise rapid reporting of clinical studies and reviews in COPD. Special focus is given to the pathophysiological processes underlying the disease, intervention programs, patient focused education, and self management protocols.

\section{Dovepress}

This journal is indexed on PubMed Central, MedLine and CAS. The manuscript management system is completely online and includes a very quick and fair peer-review system, which is all easy to use. Visit http://www.dovepress.com/testimonials.php to read real quotes from published authors. 